\title{
Coresidence Among Older Adults and Their Adult Children
}

\author{
Author: Kasey J. Eickmeyer \& Susan L. Brown
}

Despite extensive research on young adult coresidence, little is known about coresidence among older adult parents and their midlife adult children. Using the 1988-2018 Current Population Survey (CPS) Annual Social and Economic Supplement, we examine the coresidential status of parents aged 60 and older across three decades. Specifically, we distinguish between households in which parents coreside with an adult child over the age of 40 versus those in which parents do not reside with an adult child. Coresident households provide benefits for both older adults and their adult children and may reflect a coping strategy in the face of economic hardship (Kahn et al., 2013; Moen \& Wethington, 1992). In this Family Profile, we explore the varied characteristics of parents in 2018 according to their coresident status. These characteristics include retirement, health, physical and cognitive difficulties, and income. This Family Profile offers insight into the changing living arrangements of older adult parents and their midlife adult children. In 2018, nearly $8 \%$ of older adults lived with a midlife adult child. Parent-child coresidence may be a response to health difficulties or financial insecurity.

\section{Coresidence Among Older Adult Parents and Midlife Adult Children, 1988-2018}

- The number of parents (aged 60 and up) coresiding with at least one adult child over the age of 40 increased from 1.9 million to 5.4 million over the past 30 years.

0 The increase was most pronounced between 1988 and 1998 , from $5.0 \%$ to $7.3 \%$-- almost a $50 \%$ rise. In $2018,7.6 \%$ of older adults lived with a midlife-aged child.

- The average age of older adults who coresided with an adult child was 75 compared to 70 among those who were not coresiding with an adult child.
Figure 1. 30-Year Trend in Coresidence Among Older Adult Parents (60+) and Midlife Adult Children (40+)

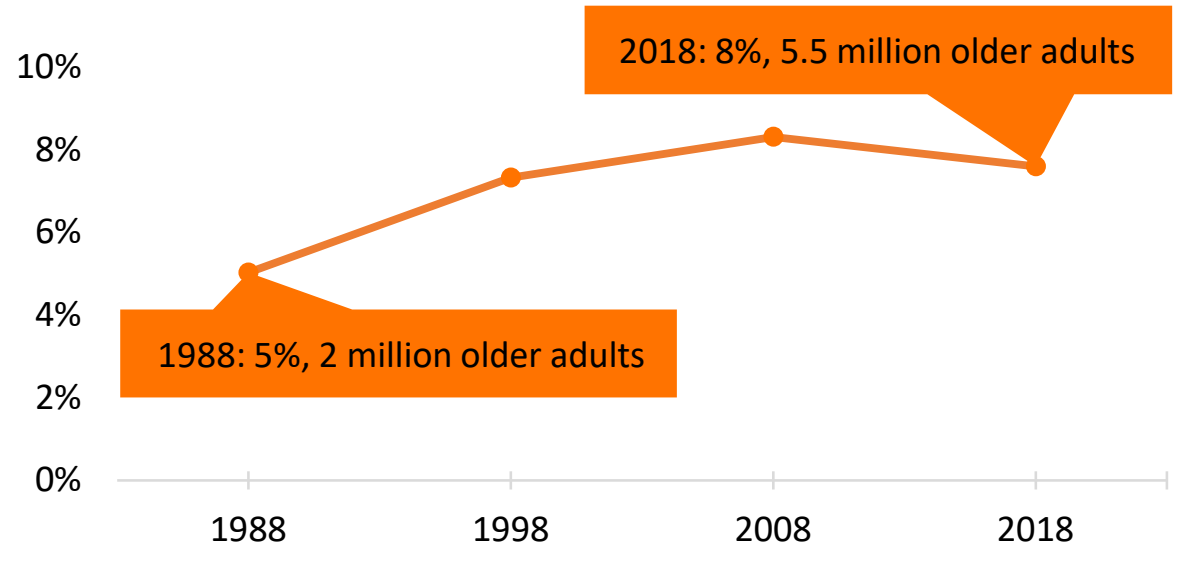

Source: NCFMR analyses of CPS ASEC, 1988-2018

\section{Personal \& Household Income}

- Intergenerational coresidence seems to benefit parents financially.

o Older parents who were coresiding with an adult child in 2018 had personal incomes that were nearly half that of those who were living in a separate residence from their children $(\$ 25,880$ compared to $\$ 43,605$, respectively).

o Household incomes among older parents coresiding with a child were higher than household incomes of older parents living separately in 2018.
Figure 2. Average Personal and Household Income of Parents Aged 60+ by Coresidence with Midlife Adult Child

Not coresiding Coresiding

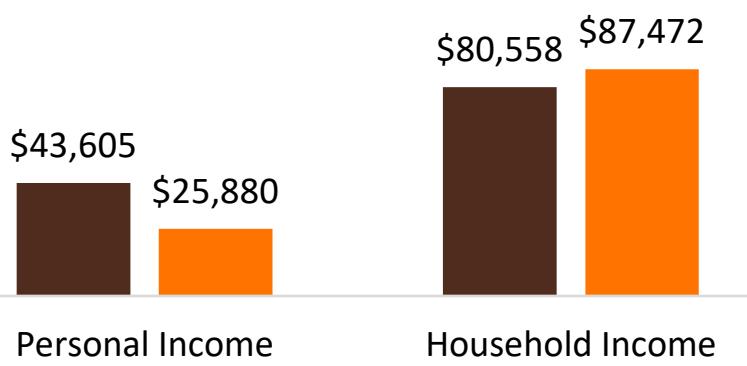




\section{Coresidence According to Retirement, Health Status, and Physical/Cognitive Difficulty}

\section{Retirement Status}

- The majority of parents over age 60 were retired. The share retired varied by whether they were coresiding with an adult child in 2018.

o A majority $(75 \%)$ of those coresiding with an adult child were retired, compared to less than half $(41 \%)$ of those not living with a child.
Health

- Regardless of residency, most parents over the age of 60 reported being in good, very good, or excellent health. However, a larger share of parents coresiding with a child reported fair or poor health than those not coresiding with a child (36\% compared to $25 \%$, respectively).

\section{Physical/Cognitive Difficulty}

- Parents over 60 typically did not have cognitive or physical difficulties.

- Among parents coresiding with an adult child, $36 \%$ reported any physical or cognitive difficulty compared to $24 \%$ of those not coresiding with an adult child.

Figure 3. Retirement, Health Status, and Physical/Cognitive Difficulty of Parents Aged 60+ by Coresidence Status, 2018

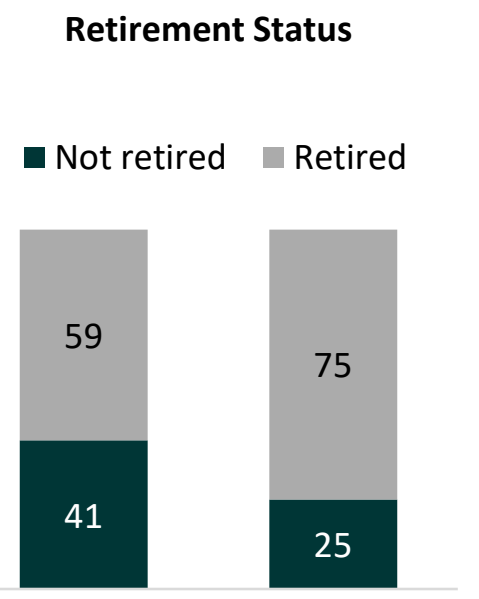

Not coresiding Coresiding with with child child
Health

Fair/poor

Good/Very good/Excellent

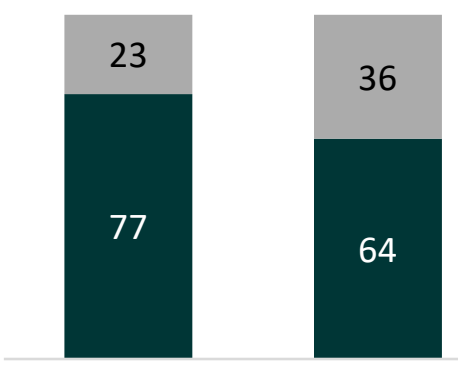

Not coresiding Coresiding with with child child
Physical/Cognitive

Difficulty

No difficulty $\quad$ Has difficulty

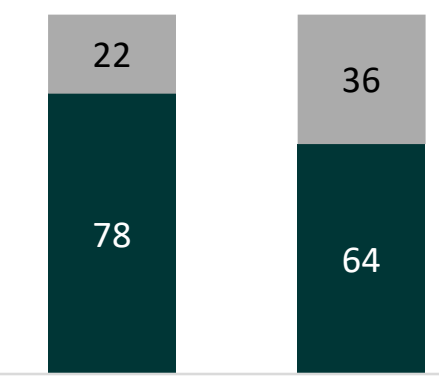

Not coresiding Coresiding with with child child

Source: NCFMR analyses of CPS ASEC, 2018

\section{Data Sources:}

Flood, S., King, M., Rodgers R., Ruggles, S, and Warren, J. R. (2018). Integrated Public Use Microdata Series, Current Population Survey: Version 6.0. Minneapolis, MN: IPUMS, 1988-2018. https://doi.org/10.18128/D030.V6.0

\section{References:}

Kahn, J. R., Goldscheider, F., \& García-Manglano, J. (2013). Growing parental economic power in parent-adult child households: Coresidence and financial dependency in the United States, 1960-2010. Demography, 50(4), 1449-1475.

Moen, P., \& Wethington, E. (1992). The concept of family adaptive strategies. Annual review of sociology, 18(1), 233-251.

\section{Suggested Citation:}

Eickmeyer, K. J. \& Brown, S. L. (2019). Coresidence among older adults and their adult children. Family Profiles, FP-19-19.

Bowling Green, OH: National Center for Family \& Marriage Research. http://doi.org/10.25035/ncfmr/fp-19-19 